\title{
Antioxidant potential of extracts from different agro wastes: Stabilization of corn oil
}

\author{
By Bushra Sultana ${ }^{1}$, Farooq Anwar ${ }^{1 *}$, Muhammad Rafique Asi ${ }^{2}$ \\ and Shahzad Ali Shahid Chatha'
}

${ }^{1}$ Department of Chemistry, University of Agriculture, Faisalabad-38040, Pakistan.

${ }^{2}$ Nuclear Institute for Agriculture and Biology (NIAB), Faisalabad, Pakistan.

( ${ }^{*}$ Corresponding author: fqanwar@yahoo.com)

\section{RESUMEN}

Potencial antioxidante de extractos de residuos agroalimentarios: estabilización de aceite de maíz.

En este studio se determinó el potencial antioxidante de extractos de methanol al $80 \%$, de distintos resíduos de granada, manzana, frutos cítricos, maíz, trigo y arroz. Los rendimientos de los extractos variaron en un amplio rango (8.89 a $29.9 \mathrm{~g} / 100 \mathrm{~g}$ de materia seca). La cantidad total de compuestos fenólicos, de flavonoides y de flavonoles, así como la capacidad para secuestrar radicales y la inhibición de la oxidación del ácido linoleico varió significativamente $(P<$ 0.05). El extracto de piel de granada contenía las cantidades más elevadas de compuestos fenólicos, de flavonoides y de flavonoles y exhibió la capacidad antioxidante más elevada seguido del de piel de manzana, piel de cítricos, piel de plátano, mazorca de maíz, salvado de trigo, salvado de arroz, cáscara de trigo y cáscara de arroz. Igualmente, se estableció la actividad antioxidante de los extractos usando aceite de maíz como sustrato. Muestras de aceite estabilizadas con los distintos extractos $(600 \mathrm{mg} / \mathrm{kg})$ fueron sometidas a oxidación acelerada $\left(60{ }^{\circ} \mathrm{C}\right.$ en horno durante 30 días con ciclos de calentamiento de $8 \mathrm{~h} /$ día) y periódicamente se determinaron los siguientes índices: dienos y trienos conjugados, índice de p-anisidina e índice de peróxidos. Finalmente, se estudiaron las correlaciones entre los resultados de los distintos ensayos y los niveles de compuestos con acción antioxidante, destacando los extractos de pieles de fruta por su mayor contenido en compuestos fenólicos, flavonoides y flavonoles, e igualmente por su potencia para aumentar la estabilidad oxidativa del aceite de maíz.

PALABRAS CLAVE: Aceite de maíz - Extracción Fenoles y flavonoides totales - Flavonoles - Inhibición (\%) - Parámetros de oxidación - Radical DPPH.

\section{SUMMARY}

Antioxidant potential of extracts from different agro wastes: Stabilization of corn oil

The antioxidant potential of $80 \%$ methanolic extracts of some agro wastes (pomegranate peel, apple peel, banana peel, citrus peel, corncob, wheat husk, wheat bran, rice bran, and rice hull) was assessed. The yields of the extracts varied over a wide range (8.83 to $29.9 \mathrm{~g} / 100 \mathrm{~g}$ of dry weight). TPC, TFC, total flavonols (kaempeferol, quercetin, myricetin;
HPLC method), DPPH radical scavenging and inhibition of linoleic acid peroxidation for the extracts varied significantly $(P<0.05)$ ranging from $0.16-36.40,0.026-4.89 \mathrm{~g} / 100 \mathrm{~g}$ of dry matter, $1.06-2622.41 \mathrm{mg} / \mathrm{Kg}$ of dry matter, $11.2-52.6$, and $64.8-96.4 \%$, respectively. Pomegranate peel extract, offering the highest TPC, TFC, and total flavonols exhibited superior antioxidant activity followed by apple peel, citrus peel, banana peel, corncob, wheat bran, rice bran, wheat husk, and rice hull. Furthermore, the antioxidant effectiveness of the extracts was assessed using corn oil (CO) as the oxidation substrate. $\mathrm{CO}$ samples stabilized with extracts at a concentration of $600 \mathrm{ppm}(\mathrm{w} / \mathrm{w})$ were subjected to accelerated aging $\left(60^{\circ} \mathrm{C}\right.$, oven heating, 30 days; $8 \mathrm{~h}$ heating cycle per day), and analyzed periodically for the extent of oxidative alterations following the measurement of conjugated dienes (CD), conjugated trienes (CT), p-anisidine and peroxide values. The correlation between the results of different antioxidant assays and oxidation parameters investigated in the present study indicated that fruit peel extracts, exhibiting higher TPC, TFC, flavonol and scavenging power, were also more potent for enhancing the oxidative stability of corn oil.

KEY-WORDS: Corn oil - DPPH radical - Extraction Flavonols - HPLC - Inhibition(\%) - Oxidation parameters Total phenolics and flavonoids.

\section{INTRODUCTION}

Lipid peroxidation that results from the reaction between unsaturated fatty acids and molecular oxygen is a severe problem for the oil and fat industry. It not only deteriorates the quality of fats and fatty foods and brings about chemical spoilage, it also produces free radicals and reactive oxygen species (ROS) which are reportedly associated with carcinogenesis, mutagenesis, inflammation, aging and cardiovascular diseases (Sikwese and Duodu, 2007; Wang et al., 2003). Synthetic antioxidants such as butylated hydroxyanisole (BHA), butylated hydrxytolune (BHT) and tertiary butylhydroquinone (TBHQ) have been widely used for the preservation and protection of oilbased products against oxidation, however, their use is discouraged due to the perceived carcinogenic potential (Siddhuraju, 2007; Sultana et al., 2007). 
Currently, the applications of plant-derived natural antioxidants such as phenolic acid, flavonoids and tocopherols in foods, as well as preventive and therapeutic medicine, is gaining recognition because of their anticarcinogenic potential and other health-promoting effects (Choi et al., 2007; Fan et al., 2007; Iqbal et al., 2007; Siddhuraju, 2007). Such natural antioxidant substances are believed to play a potential role in interfering with the oxidation process by reacting with free radicals, chelating catalytic metals and scavenging oxygen in foods and biological systems (Kim, 2005). The antioxidant activity of this manifold group of plant-based natural antioxidants has been studied in vitro and vivo, and depends on the individual structure, position and degree of hydroxylation (Shahidi, 1997). Following the new trends, in recent years, the use of plant extracts as antioxidant additives for improving the oxidative stability and shelf-life of vegetable oils and fats has also attracted a great deal of scientific interest (Anwar et al., 2007; Siddiq et al., 2005).

Several types of plant materials such as vegetables, fruits, leaves, oilseeds, cereal crops, barks, roots, spices and herbs have been sought out for their potential antioxidants (Choi et al., 2007; lqbal et al., 2007; Kim, 2005; Sikwese and Duodu, 2007; Sultana et al., 2007; Wang et al., 2003). However, relatively less information is available on the antioxidant principles of the agro wastes which are usually discarded in huge quantities. As a result, in the last few years, increased attention has been focused on the antioxidant prospective of food processing products and agro-industrial wastes (Iqbal et al., 2007; Moure et al., 2001; Zia-ur-Rehman, 2006). The determination of antioxidants in peels, brans, seed coats and oilseed residues etc. has been gaining importance with the recognition that these parts of the fruits and seeds are often rich sources of natural antioxidants.

Pakistan, being an agricultural country is blessed with medicinally or economically important flora and agricultural crops. There are a number of agro wastes, fruit processing products and cereal residual sources for bioprospecting and screening of antioxidant components. This study was an attempt to investigate different indigenously available agro wastes as potential sources of natural antioxidants and to appraise their efficacy for stabilizing corn oil.

\section{EXPERIMENTAL}

\subsection{Materials}

Samples of refined-bleached-deodorized (RBD) corn oil, without citric acid or other additives and corncob (Zea mays, var. neelam) were procured from Rafhan Maize Products, Pvt. Ltd., Faisalabad, Pakistan; rice bran and rice hull (Oryza sativa, var. super kernel) from Ahmed Rice Mill, Chiniot,
Pakistan; wheat bran and wheat husk (Triticum sativum, var. inqalab) from Ayub Agriculture Research Institute, Faisalabad, Pakistan; peels of citrus (Citrus reticulata, var. kinow), apple (Malus pumila, var. skysuper), banana (Musa sapientum, var. basrai) and pomegranate (Punica granatum, var. qandhari) were obtained from local fruit market sources of Faisalabad, Pakistan. The varieties of agricultural materials were checked, further identified and authenticated by Professor Dr. Muhammad Ashraf, Dean Faculty of Basic Sciences, Department of Botany, University of Agriculture, Faisalabad, Pakistan. HPLC grade flavonol standards (kaempeferol, quercetin, myricetin), ( $\left.{ }_{-}^{+}\right)$catechin, TBHQ (99.0\%), BHT $(99.0 \%)$, Folin-Ciocalteu phenol reagent $(2 \mathrm{~N})$, gallic acid $(98.0 \%), 1,1$,-diphenyl-2-picrylhydrazyl (DPPH) $(90.0 \%)$ and linoleic acid $(99.0 \%)$ were of Sigma Chemicals Co. (St, Louis, MO, USA). All other chemicals (analytical grade) i.e. anhydrous sodium carbonate, sodium hydroxide, sodium nitrite, ferrous chloride, ammonium thiocyanate, aluminum chloride, potassium dihydrogen phosphate, dipotassium hydrogen phosphate, isooctane, chloroform, acetic acid, potassium iodide, and sodium thiosulphate used in this study were purchased from Merck (Darmstadt, Germany), unless otherwise stated.

\subsubsection{Dry matter determination}

Owing to the varying water contents of different plant materials, all calculations were made on dry mass basis. For the determination of dry matter, all samples were dried under a fan at ambient temperature using the passive air-drying technique for 1- 2 weeks, until constant weight was achieved.

\subsection{Preparation of Extracts and Evaluation of Antioxidant Activity}

\subsubsection{Extraction of plant materials}

Air-dried plant materials were ground into a fine powder using a commercial blender ((TSK-949, Westpoint, France), except for rice bran and wheat bran, which were processed as such. The material that passed through an 80-mesh sieve was used for extraction purposes. Powdered material $(20 \mathrm{~g})$ for each sample was extracted with $200 \mathrm{~mL}$ of $80 \%$ methanol, overnight at room temperature using an orbital shaker (Gallenkamp, UK). The extracts were separated from the residue by filtering through Whatman No. 1 filter paper. The residues were extracted twice with the same solvent and extracts pooled. The pooled extracts were concentrated to dryness under reduced pressure at $45{ }^{\circ} \mathrm{C}$, using a rotary evaporator (EYELA, N-N Series, Rikakikai Co. Ltd. Tokyo, Japan). The dry extracts were weighed to calculate the yield and stored in a refrigerator $\left(-4{ }^{\circ} \mathrm{C}\right)$, until used for further analyses. 


\subsubsection{Determination of total phenolics content (TPC)}

The amount of TP were assessed using FolinCiocalteu reagent (Chaovanalikit and Wrolstad, 2004). Briefly, $50 \mathrm{mg}$ of crude extract were mixed with $0.5 \mathrm{~mL}$ of Folin-Ciocalteu reagent and $7.5 \mathrm{~mL}$ deionized water. The mixture was kept at room temperature for $10 \mathrm{~min}$, and then $1.5 \mathrm{~mL}$ of $20 \%$ sodium carbonate $(\mathrm{w} / \mathrm{v})$ added. The mixture was heated in a water bath at $40{ }^{\circ} \mathrm{C}$ for 20 min and then cooled in an ice bath; absorbance was measured at $755 \mathrm{~nm}$ using a spectrophotometer (U-2001, Hitachi Instruments Inc. Tokyo, Japan). Amounts of TP were calculated using a gallic acid calibration curve within the range of $10-100 \mathrm{ppm}\left(\mathrm{R}^{2}=\right.$ 0.9986). The results were expressed as gallic acid equivalents (GAE) g/100g of dry matter. All samples were analyzed thrice and results averaged.

\subsubsection{Determination of total flavonoids (TF)}

TF were determined following the procedure of Dewanto et al., (2002). One milliliter of aqueous extract containing $0.01 \mathrm{~g} / \mathrm{mL}$ of dry matter was placed in a $10 \mathrm{~mL}$ volumetric flask, then $5 \mathrm{~mL}$ of distilled water were added followed by $0.3 \mathrm{~mL}$ of $5 \%$ $\mathrm{NaNO}_{2}$. After $5 \mathrm{~min}, 0.6 \mathrm{~mL}$ of $10 \% \mathrm{AlCl}_{3}$ were added. After another $5 \mathrm{~min} 2 \mathrm{~mL}$ of $1 \mathrm{M} \mathrm{NaOH}$ were added and the volume made up with distilled water. The solution was mixed and absorbance was measured at $510 \mathrm{~nm}$ using a spectrophotometer (U2001, Hitachi Instruments Inc. Tokyo, Japan).TF amounts were expressed as $( \pm)$ catechin

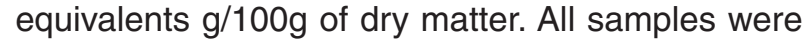
analyzed thrice and results averaged.

\subsubsection{DPPH. Scavenging assay}

The free radical scavenging activity of extracts was assessed using procedure the reported earlier (Sultana et al., 2007; lqbal et al., 2007). Briefly, 5.0 $\mathrm{mL}$ of a freshly prepared solution of 1, 1'-diphenyl-2picrylhydrazyl (DPPH) at concentration $0.025 \mathrm{~g} / \mathrm{L}$ were added to $1.0 \mathrm{~mL}$ of extract containing $25 \mu \mathrm{g} / \mathrm{mL}$ of dry matter in methanol. Absorbance at 0, 0.5, 1, 2, 5 and $10 \mathrm{~min}$ was measured at $515 \mathrm{~nm}$ using a spectrophotometer (U-2001, Hitachi Instruments Inc. Tokyo, Japan). The remaining amounts of DPPH radical were calculated from the calibration curve. Absorbance measured at the 5th minute was used for comparison of the radical scavenging activity of the extracts.

\subsubsection{Determination of antioxidant activity in linoleic acid system}

The antioxidant activity of extracts was also determined by measuring the oxidation of the linoleic acid system (Sultana et al., 2007; lqbal et al., 2007). $5 \mathrm{mg}$ of each extract were added separately to a solution of linoleic acid $(0.13 \mathrm{~mL})$,
$99.8 \%$ ethanol $(10 \mathrm{~mL})$ and $10 \mathrm{~mL}$ of $0.2 \mathrm{M}$ sodium phosphate buffer ( $\mathrm{pH} 7$ ). The mixture was made up to $25 \mathrm{~mL}$ with distilled water and incubated at $40{ }^{\circ} \mathrm{C}$ up to 360 hours. The extent of oxidation was measured by the peroxide value applying the thiocyanate method as described by Yen et al., (2000). Briefly, $10 \mathrm{~mL}$ of ethanol (75\% v/v), $0.2 \mathrm{~mL}$ of aqueous solution of ammonium thiocyanate $(30 \% \mathrm{w} / \mathrm{v}), 0.2 \mathrm{~mL}$ of sample solution and $0.2 \mathrm{~mL}$ of ferrous chloride $\left(\mathrm{FeCl}_{2}\right)$ solution $(20 \mathrm{mM}$ in $3.5 \%$ $\mathrm{HCl}$; v/v) were added sequentially. After $3 \mathrm{~min}$ of stirring, the absorption was measured at $500 \mathrm{~nm}$ using a spectrophotometer. A control contained all reagents with the exception of extracts. The synthetic antioxidant butylated hydroxytoluene (BHT) was used as a positive control. The percent of inhibition of linoleic acid oxidation was calculated with the following equation: $100-[$ (Abs. increase of sample at $360 \mathrm{~h} / \mathrm{Abs}$. increase of control at $360 \mathrm{~h}) \times 100]$, to express antioxidant activity.

\subsection{Sample Extraction for HPLC}

The extraction/hydrolysis of flavonols was carried out following the method of Tokusoglu et al., (2003) with slight modifications. Briefly, acidified methanol $(25 \mathrm{~mL})$ containing $1 \%(\mathrm{v} / \mathrm{v}) \mathrm{HCl}$ and $0.5 \mathrm{mg} \mathrm{mL}^{1}$ TBHQ was added to each ground (80-mesh sieve) plant material $(5 \mathrm{~g})$. $\mathrm{HCl}(1.2 \mathrm{M}, 5 \mathrm{~mL})$ was added and the mixture was stirred at $90^{\circ} \mathrm{C}$ under reflux for 2 hours to obtain aglycons of flavonol glycosides. The extract was cooled to room temperature and centrifuged (EBA 20, Hettich, Germany) at $1538 \mathrm{~g}$ (5000 rpm) for $10 \mathrm{~min}$. Upper layers were taken and sonicated for $5 \mathrm{~min}$, to remove the air. The final extracts were filtered through a $0.45-\mu m$ (Millipore) filter before injecting into HPLC.

\subsection{HPLC Separation}

A flavonol (kaempeferol, quercetin, myricetin) analysis was performed using a high-performance liquid chromatograph. An HPLC (model LC-10A, Shimadzu, Japan), equipped with two LC-10 AS pumps, SCL-10A system control unit, Rheodyne injector, CTO-10A column oven, SPD-10A UV-Vis detector and data acquisition class LC-10 software were used. A $20-\mu \mathrm{L}$ volume of the filtered sample was injected into an analytical Supelco (Supelco Inc., Supelco Park, Bellefonte, USA) ODS reverse phase $(\mathrm{C} 18)$ column $(250 \times 4.6 \mathrm{~mm} ; 5 \mu \mathrm{m}$ particle size). Two solvent systems $A$ : contained $3 \%$ triflouroacetic acid and B: contained acetonoitrile and methanol $(80: 20 \mathrm{v} / \mathrm{v})$ were used. The chromatographic separation was performed by isocratic elution of the mobile phase (mixture of solvent $A$ and $B(50: 50 \mathrm{v} / \mathrm{v})$ which was filtered under vacuum through a $0.45 \mu \mathrm{m}$ membrane before use) at a flow rate of $1.0 \mathrm{~mL} \mathrm{~min}^{-1}$ at $30{ }^{\circ} \mathrm{C}$. Detection was performed at a wavelength of $360 \mathrm{~nm}$. 
The identification of flavonols (kaempeferol, quercetin, myricetin) was carried out by comparing their retention times with those of authentic standards (Sigma Chemicals Co., St, Louis, MO, USA). Quantitative determination was carried using calibration curves of the standards. By analyzing dilution series of pure standards solutions ranging from 0.01 to $0.08 \mathrm{mg} \mathrm{L}^{-1}$, minimum quantities were determined for the flavonols. The mean value of the signal-to-noise ratio $(n=8)$ generated from the solution that just caused more than 3 times $\mathrm{S} / \mathrm{N}$ ratio was used to calculate the detection limit (based on $\mathrm{S} / \mathrm{N}=3$ ) of the corresponding flavonol. The detection limit for kaempferol, quercetin and myricetin was $0.04,0.05,0.05 \mathrm{mg} \mathrm{L}^{-1}$, respectively.

\subsection{Evaluation of Antioxidant Efficacy of Extracts Using Corn Oil as Oxidation Substrate}

\subsubsection{Stabilization of oil}

The crude concentrated methanolic extracts of each plant material were separately added to preheated $\left(50{ }^{\circ} \mathrm{C}\right)$ RBD corn oil (CO) at concentrations of $600 \mathrm{ppm}(\mathrm{w} / \mathrm{w})$. The $\mathrm{CO}$ samples were stirred for $30 \mathrm{~min}$ at $50{ }^{\circ} \mathrm{C}$ for uniform dispersion. Synthetic antioxidant (BHT) was employed at its legal limit of 200 ppm to compare the efficacy of extracts. Stabilized and control oil samples $(100 \mathrm{~mL})$ were placed in dark brown airtight glass bottles with narrow necks and subjected to accelerated storage in an electric hot air oven (IM-30, Irmeco, Germany) at $60{ }^{\circ} \mathrm{C}$ (8 hours heating cycle per day) for 30 days. All oil samples were prepared in triplicate. A CO sample, without antioxidant, was used as the control. Oil samples were taken after every 5-day interval. The oxidative deterioration level was assessed by the measurement of peroxide value (PV), conjugate dienes (CD), conjugate trienes (CT) and $p$-anisidine values.

\subsubsection{Measurement of oxidation parameters of corn oil}

Determination of the peroxide value (PV) of stabilized and control corn oil samples was made following the AOCS Official method Cd 8-53 (AOCS, 1997). Specific extinctions at 232 and 268 $\mathrm{nm}$ were determined using a spectrophotometer (U2001, Hitachi, Instruments Inc., Tokyo, Japan). Samples were diluted with iso-octane to bring the absorbance within limits $(0.2-0.8)$, and spectra were recorded at 232 and $268 \mathrm{~nm}$, and $\left(\varepsilon^{1 \%}{ }_{1 \mathrm{~cm}(\lambda)}\right)$ which was calculated following an IUPAC method II D.23 (IUPAC, 1987). The determination of the $p$ anisidine value was made following an IUPAC method II. D. 26 (IUPAC, 1987). The oil samples dissolved in iso-octane were allowed to react with the $p$-anisidine solution in acetic acid $(0.25 \% \mathrm{w} / \mathrm{v})$ for 10 minutes to produce colored complex and the absorbance values were noted at $350 \mathrm{~nm}$, using a spectrophotometer (U-2001, Hitachi Instruments Inc., Tokyo, Japan).

\subsection{Statistical Analysis}

Three samples of each plant material were taken. Each sample was analyzed individually in triplicate and data are reported as mean $(n=3 \times 3)$ $\pm \mathrm{SD}(n=3 \times 3)$. An analysis of variance ANOVA was performed using Minitab 2000 Version 13.2 statistical software (Minitab Inc. Pennysalvania, USA). Significant differences $(P<0.05)$ of means were calculated using Duncan's multiple range tests. The relationship between different antioxidant assays was described as the Pearson productmoment correlation coefficient $(r)$. Differences were considered statistically significant if $P<0.05$.

\section{RESULTS AND DISCUSSION}

\subsection{Extract yields and antioxidant activity}

The extract yield of antioxidative components from different agro wastes varied over a wide range, 8.83 to $29.9 \%$ (Table 1). The highest amounts were extracted from pomegranate peel (29.9\%), followed by banana peel $(24.6 \%)$, corncob $(21.6 \%)$, citrus peels $(21.5 \%)$, rice bran $(20.5 \%)$, apple peel $(16.4 \%)$, wheat bran $(12.7 \%)$, wheat husk $(9.41 \%)$, and rice hull (8.83\%). Okonogi et al., (2007) investigated the extract yield of banana and pomegranate peels with $95 \%$ ethanol and found it to be 7.66 and $6.21 \%$, respectively. The literature revealed the amount of extractable components using methanol from citrus peels as $19.87 \%$ (Zia-urRehman, 2006) and rice bran $13.60 \%$ (Chatha et al., 2006) and that of wheat bran with ethanol was10.6\% (Liyana-Pathirana and Shahidi, 2007). Our present analysis revealed somewhat higher extract yields of the investigated plant materials.

Variations in the yield of extracts from different plant materials might be attributed to the availability of different extractable components, defined by the chemical composition of the plant, nature of the soil and agro-climatic conditions (Hsu et al., 2006). Among other parameters, effectiveness of the extracting solvent to dissolve endogenous compounds might also be a contributing factor.

The amount of total phenolics (TP) determined in $80 \%$ methanolic extracts of different agro wastes is shown in Table 1. The contents of TP were determined by means of the Folin-Ciocalteu reagent (FCR) assay, commonly known as the total phenols (or phenolic) assay. The total phenol assay is often used for the assessment of the antioxidant activity of plant extracts due to its ease, simplicity, and reproducibility, apart from undefined chemical nature of FCR. Several researchers have used this assay to determine total phenolics and often established a good linear correlation between the "total phenolic profile" and antioxidant activity 
Table 1

Yield of extract ( $\mathrm{g} / 100 \mathrm{~g}$ of dry matter), total phenolic contents GAE (g/100g of dry matter), total flavonoids CE (g/100g of dry matter), percent DPPH radical remaining and percent inhibition of peroxidation of different agro wastes

\begin{tabular}{lccccc}
\hline \multicolumn{1}{c}{$\begin{array}{c}\text { Agro } \\
\text { waste }\end{array}$} & $\begin{array}{c}\text { Yield } \\
\text { of extract }\end{array}$ & $\begin{array}{c}\text { Total } \\
\text { phenolic contents }\end{array}$ & $\begin{array}{c}\text { Total } \\
\text { flavonoid contents }\end{array}$ & $\begin{array}{c}\text { DPPH } \\
\text { remaining }\end{array}$ & $\begin{array}{c}\text { Inhibition of } \\
\text { peroxidation }\end{array}$ \\
\hline Pomegranate peels & $29.9^{\mathrm{f}} \pm 0.8$ & $36.4^{\mathrm{c}} \pm 0.7$ & $4.89^{\mathrm{a}} \pm 0.15$ & $11.2^{\mathrm{a}} \pm 0.8$ & $96.4^{\mathrm{e}} \pm 1.9$ \\
Apple peels & $16.4^{\mathrm{c}} \pm 0.9$ & $3.9^{\mathrm{b}} \pm 0.6$ & $2.21^{\mathrm{b}} \pm 0.13$ & $15.6^{\mathrm{b}} \pm 0.5$ & $88.2^{\mathrm{d}} \pm 3.7$ \\
Banana peels & $24.6^{\mathrm{e}} \pm 0.4$ & $1.1^{\mathrm{b}} \pm 0.3$ & $0.62^{\mathrm{c}} \pm 0.03$ & $23.6^{\mathrm{c}} \pm 1.8$ & $82.7^{\mathrm{c}} \pm 4.1$ \\
Wheat husk & $9.4^{\mathrm{a}} \pm 0.6$ & $0.3^{\mathrm{a}} \pm 0.2$ & $0.05^{\mathrm{d}} \pm 0.05$ & $46.2^{\mathrm{e}} \pm 1.9$ & $68.2^{\mathrm{ab}} \pm 3.6$ \\
Wheat bran & $12.7^{\mathrm{b}} \pm 0.5$ & $0.4^{\mathrm{a}} \pm 0.2$ & $0.04^{\mathrm{d}} \pm 0.04$ & $28.9^{\mathrm{cd}} \pm 0.8$ & $70.7^{\mathrm{ab}} \pm 3.5$ \\
Corncob & $21.6^{\mathrm{d}} \pm 1.2$ & $1.5^{\mathrm{ab}} \pm 0.4$ & $0.05^{\mathrm{d}} \pm 0.02$ & $26.1^{\mathrm{c}} \pm 1.4$ & $72.5^{\mathrm{b}} \pm 2.8$ \\
Rice bran & $20.5^{\mathrm{d}} \pm 0.7$ & $0.4^{\mathrm{a}} \pm 0.2$ & $0.03^{\mathrm{d}} \pm 0.04$ & $31.6^{\mathrm{d}} \pm 1.1$ & $69.5^{\mathrm{ab}} \pm 2.6$ \\
Rice hull & $8.8^{\mathrm{a}} \pm 0.6$ & $0.2^{\mathrm{a}} \pm 0.1$ & $0.03^{\mathrm{e}} \pm 0.03$ & $52.6^{\mathrm{f}} \pm 0.7$ & $64.8^{\mathrm{a}} \pm 3.9$ \\
Citrus peel & $21.5^{\mathrm{d}} \pm 0.5$ & $2.4^{\mathrm{b}} \pm 0.3$ & $1.92^{\mathrm{b}} \pm 0.12$ & $21.8^{\mathrm{c}} \pm 1.4$ & $86.9^{\mathrm{cd}} \pm 1.8$ \\
\hline
\end{tabular}

Values (mean $\pm \mathrm{SD})$ are the average of triplicate samples, analyzed individually in triplicate $(\mathrm{n}=3 \times 3),(P<0.05)$ :Different letters in superscript indicate significant differences. GAE, Gallic acid equivalents. CE, Catechin equivalents.

(Huang et al., 2005). The contents of TP, ranging from 0.2 to $36.40 \mathrm{GAE}(\mathrm{g} / 100 \mathrm{~g}$ of dry matter), differed significantly $(P<0.05)$ among various plant materials. Of the different residual sources investigated in the present analysis, fruit peels contained relatively higher amounts of TP. Our results are consistent with a previous report ( $\mathrm{Li}$ et al., 2005) which reveals that peel tissues usually contain larger amounts of phenolis, anthocynins and flavonols.

Within peels, the highest TP were found in pomegranate $(36.40 \%)$, followed by apple $(3.90 \%)$, citrus $(2.4 \%)$, and banana $(1.1 \%)$. The results of TP for pomegranate peels in the present work were found to be higher than those reported by Li et al., (2005), however, lower than that of Negi et al., (2003), while that of apple were higher than the earlier report (Leontowicz et al., 2002), although comparable with the results of Wolfe and Liu, (2003). Citrus and banana peels also contained appreciable amounts of TP, which were relatively higher than earlier reports (Anagnostopoulou et al., 2006; Someya et al., 2002).

The TP contents of rice bran and wheat bran were found to be 0.4 and $0.4 \%$, respectively. Iqbal et al., (2005) reported the TP of four varieties of rice bran indigenous to Pakistan to range from 0.251 $0.359 \mathrm{~g} / 100 \mathrm{~g}$. The TP of wheat bran in the present investigation were found to be comparable with earlier reports $(0.212-0.37 \mathrm{~g} / 100 \mathrm{~g}$ ) (lqbal et al., 2007), however, the current level was greater than that reported by Zhou and Yu, (2004) (0.063-0.263 $\mathrm{g} / 100 \mathrm{~g})$. The lowest contents of TP $(0.2$ and $0.3 \%)$ were observed in the samples of rice hull, and wheat husk, respectively. Corncob also offered an appreciable amount of TP $(1.5 \%)$ which were found to be lower than fruit peels but higher than rice hull, rice bran, wheat bran, and wheat husk.

Total flavonoid contents (TFC) also varied significantly $(P<0.05)$ among different agriculture waste materials ranging from 0.03-4.89 CE (g/100 gm of dry matter) (Table 1). All fruit peels exhibited greater concentrations of flavonoids with the highest contents in pomegranate peels (4.89), followed by apple (2.21), and citrus (1.92) peels, however, a lower amount was observed in banana (0.62). On the other hand, total flavonoid contents were found to be quite low in cereal by- products ranging from $0.03-0.05 \mathrm{CE}(\mathrm{g} / 100 \mathrm{gm}$ of dry matter), which also contained lower amounts of TP. Significant $(p<0.05)$ variations in TP and TF amounts among different plant materials might be attributed to factors such as natural chemical composition, maturity at harvest, soil state and conditions of post-harvest storage (Huang et al., 2005). However, a good correlation ( $r=0.901, p<$ 0.05 ) between TF and TP was observed in the present analysis (Table 4).

The results of DPPH scavenging activity are shown in Table 1. DPPH radical is commonly used for the assessment of antioxidant activity. The DPPH radical with deep violet color gives intensive absorption within the range of $515-528 \mathrm{~nm}$. This test is based on the ability of the DPPH (I, 1diphenyl-2-picrylhydrazyl) to react with hydrogen donor species such as phenolics. Upon receiving a proton, it loses its color and becomes yellow. As the concentration of phenolic compounds or degree of hydroxylation of the phenolic compounds increases, their DPPH radical scavenging activity also increases, the antioxidant efficacy of a typical plant material can be predicted. Because these radicals are very sensitive to the presence of hydrogen donors, the whole system operates at a very low concentration; with it, a large number of samples can be tested in a short time (Roginsky and Lissi, 2005). Absorbance in this assay was recorded at 0.5 to 10 min time intervals from the initiation of the reaction. Observed scavenging activity was similar at the beginning of the reaction and changed with the increase in reaction time until stabilized after $10 \mathrm{~min}$. Significant $(P<0.05)$ differences among different extracts were observed at the $5^{\text {th }}$ minute of reaction (Table 1). The DPPH scavenging activity of each sample was reported as the percent of DPPH remaining, with a higher value of percent of $\mathrm{DPPH}$ 
remaining associated to a weaker antioxidant activity.

All extracts possessed the free radical scavenging properties but to varying degrees. The remaining amount (\%) of $\mathrm{DPPH}^{-}$radical at $5 \mathrm{~min}$ after initiation of the reaction ranged from 11.2 to $52.6 \%$. Results from the present analysis show that the pomegranate peel extract exhibited maximum scavenging activity followed by apple peel, citrus peel, banana peel, corncob, wheat bran, rice bran, wheat husk, and rice hull. The large amount of phenolics contained in peel extract may account for its strong antioxidant activity. In the investigations of antioxidant activities of certain fruit peel extracts including pomegranate, and banana, pomegranate peel exhibited the highest DPPH. scavenging activity (Okonogi et al., 2007). The antioxidant activity of pomegranate peel extracts might be attributed to the presence of polyphenols, such as ellagic tannins, ellagic acid and gallic acid (Gil et al. 2000). Apple peel also exhibited good radical scavenging activity, which is in accordance to the previous findings of Abrosca et al., (2007) who reported that apple peel extract caused a $78 \%$ reduction in DPPH from the initial DPPH.

The radical scavenging activity of wheat bran (var. inqalab) (28.9\% DPPH remaining) in the present study was found to be slightly lower than the var. Punjab-9 (24\%), however, it was comparable with that of var. Bhakkar 2002 (30\%) (lqbal et al., 2007). DPPH radical scavenging activity of wheat bran in the present analysis was found to be greater than that reported by Cheng et al. (2006) (35.6\% DPPH remaining) but lower than that reported by Zhou and Yu, (2004) (16.87\% DPPH remaining), while that of rice bran $(31.6 \%$ DPPH remaining) was found to be lower than the literature reports (Iqbal et al., 2005) (20.6-30.6\% DPPH remaining).

It has been proven that the free radical scavenging activity of plant extracts is mainly ascribed to the concentration of phenolic compounds present in the plants (Moure et al., 2001). Several studies showed good correlation between the total phenolic contents and antioxidant activity of plant extracts (Huang et al., 2005). Significant linear correlation of TP $(r=-0.552, P<$ $0.05)$, TF ( $r=-0.720, P=0.03)$, and total flavonol contents $(r=-0.725, P<0.02)$ (table. 4) with DPPH scavenging activity were also observed in the present work.

The inhibition of linoleic acid oxidation as exhibited by different plant extracts (Table 1 ) ranged from $64.8-96.4 \%$, whereas BHT provided inhibition at the level of $84.7 \%$. The sample with the greatest level of \% inhibition of peroxidation was the pomegranate peel extract $(96.4 \%)$, followed by apple $(88.2 \%)$, citrus $(86.9 \%)$, and banana $(82.7 \%)$ extracts. On the other hand the lowest inhibition of peroxidation was offered by wheat husk (68.2\%) and rice hull $(64.8 \%)$.

The variation in the level \% inhibition of different plant materials can be explained by their varying total phenolic concentration. Correlation analyses $(r=0.686 ; r=0.909, r=0.920$ at $p=0.05$ ) (Table. 4 ) in the present investigation also indicated a good relationship between TP, TF, and total flavonol contents with antioxidant activity determined in terms of the measurement of percent inhibition of peroxidation. Lower levels of \% inhibition of peroxidation offered by the samples (wheat bran, rice bran, wheat husk, rice hull and corn cob) could be explained by the lower concentrations of phenolic compounds in these materials. Major phenolics generally present in these samples are hydroxybenzoate and hydroxycinamate that are considered to exhibit low antioxidant activity as compared to anthocyanins and flavonoids (Kahkonen et al., 1999). A few reports in the literature revealed that the antioxidant activity of some of these plant materials is based on their inhibition of peroxidation. The literature revealed that different varieties of rice bran inhibited lipid peroxidation up to $90 \%$ (lqbal et al., 2005). This variation may be due to differences in rice bran varieties, solvent used or the extraction procedure adopted in both of these studies.

\subsubsection{Flavonol contents in agro wastes}

The data for flavonol (myricetin, quercetin, kaempeferol) contents of different agro wastes are presented in Table 2. The results show a wide variation in the levels of individual flavonols (myricetin, quercetin, kaempeferol) among different agriculture wastes. Myricetin was the dominant flavonol detected in most of the samples, except rice bran and corncob and its concentration varied from 32.85 to $2495.89 \mathrm{mg} \mathrm{kg}^{-1}$. The highest levels were found in pomegranate peel (2495.89), followed by citrus peel (1102.39), banana peel (666.68), apple peel (493.44), and rice hull (32.59). However, myricetin was not detected in rice bran, wheat bran, wheat husk and corncob.

The levels of quercetin and kaempferol in different agricultural waste materials varied widely ranging from 24.11-415.09 and 1.06-102.33 mg kg 1 of dry matter, respectively. The highest quercetin levels were observed in apple peel (415.09), followed by wheat husk (107.34), corncob (102.51), wheat bran (88.75), and pomegranate peel (24.11); while the highest kaempferol levels were detected in pomegranate peel (102.33), followed by wheat bran (52.32), apple peel (51.54), and rice bran (1.06). On the other hand, quercetin and kaempferol were not detected in the present analysis of citrus peels which is in contrast to the findings of Wang et al., (2007) who reported that the quercetin and kaempferol contents in different varieties of citrus ranged from 61-573 and 9-1035 $\mathrm{mg} / \mathrm{kg}$ of dry matter, respectively. Rice hull, wheat husk, citrus and banana peels did not exhibit any amounts of quercetin and kaempferol either.

Overall, the results of HPLC indicate that all fruit peels contain good levels of total flavonols as 
Table 2

Flavonol contents ( $\mathrm{mg} / \mathrm{kg}$ of dry matter) of different agro wastes

\begin{tabular}{|c|c|c|c|c|}
\hline Agro waste & Myricetin $^{A}$ & Quercetin $^{B}$ & Kampeferol $^{\mathrm{C}}$ & Total flavonols \\
\hline Rice (bran) & ND & ND & $1.06 \pm 0.04$ & 1.06 \\
\hline Rice (hull) & $32.6 \pm 1.0$ & ND & ND & 32.6 \\
\hline Wheat (bran) & ND & $88.8 \pm 2.7$ & $52.3 \pm 2.1$ & 141.1 \\
\hline Wheat (husk) & ND & $107.3 \pm 3.2$ & ND & 107.3 \\
\hline Corn cob $^{\mathrm{e}}$ & ND & $102.5 \pm 4.1$ & ND & 102.5 \\
\hline Citrus (peel) ${ }^{b}$ & $1102.4 \pm 44.1$ & ND & ND & 1102.4 \\
\hline Banana (peel) ${ }^{d}$ & $666.7 \pm 20.0$ & ND & ND & 666.7 \\
\hline Pomegranate (peel) ${ }^{a}$ & $2495.9 \pm 25.0$ & $24.1 \pm 0.7$ & $102.4 \pm 4.1$ & 2622.4 \\
\hline Apple (peel) ${ }^{c}$ & $493.4 \pm 9.9$ & $415.1 \pm 8.3$ & $51.5 \pm 1.1$ & 960.0 \\
\hline
\end{tabular}

Values (mean \pm SD) are average of triplicate samples, analyzed individually in triplicate $(n=3 \times 3),(P<0.05)$; Small and capital alphabets in superscript indicate significant differences among agro wastes and flavonols, respectively. ND, Not detected.

compared with cereal by-products. The presence of high amounts of flavonols in fruit peels is in agreement with the previous reports which revealed that fruit peels had higher levels of phenolis, anthocynins and flavonols (Li et al., 2006). A correlation analysis (Table 4) of flavonol contents with those of TP and TF $(r=0.909$ and $r=0.987$ at $p<0.05$, respectively) also showed that samples which have greater amounts of TP and TF also exhibit a greater proportion of flavonols.

It is worth noting that samples which demonstrated greater antioxidant activity are all rich in phenolics, suggesting that these compounds might be contributing to this activity. Pomegranate is a rich source of anthocyanins (a glycosylated form of anthocyanidins). Because of their ortho-dihydroxy structure, cyanidin glycosides offer good antioxidant activity. Therefore, the higher antioxidant activity of pomegranate might be attributed to its cyanidin glycoside contents (Karadeniz et al., 2005). The antioxidant activity of apples is also associated with their concentration of anthocyanins and flavonoids (Wolfe and Liu, 2003). Anthocyanins are the main phenolic compounds present in the peel of a red apple (Karadeniz et al., 2005). The antioxidant activity of citrus peel may be attributed to the presence of phenolic compounds such as flavonones, flavone glycosides, polymethoxylated flavones, hydroxy cinnamate and other miscellaneous phenolic glycosides and amines (Ziaur-Rehman, 2006). However, some authors have suggested that the antioxidant activity of a plant material may be attributed to their gallo-derivative contents. This is the case with bananas, which are high in gallocatechins (Someya et al., 2002).

\subsection{Antioxidant potential of agro waste extracts for the stabilization of corn oil}

After preliminary assessment of antioxidant efficacies of different extracts, the effectiveness of the extracts towards the stabilization of corn oil was also examined. The magnitude of oxidative alteration in the stabilized corn oil was followed by the measurement of conjugated dienes, conjugated trienes, peroxide values and $p$-anisidine values.

Peroxide value is an indicator of the extent of primary oxidation products in oil (Anwar et al., 2007; Chatha et al., 2006). The peroxide values of the stabilized and control (without extract) corn oil, over an incubation period of 30 days at $60{ }^{\circ} \mathrm{C}$ is shown in Figure 1. It is evident from the results that the addition of both the synthetic antioxidant at a concentration of $200 \mathrm{ppm}$ and methanolic extracts from different plant materials at 600 ppm inhibited the oxidation in corn oil significantly $(P<0.05)$ as compared with the control. The results indicate (Table 3 ) that the addition of antioxidant extracts from plant materials decreased the rise in PV by $42.5-70.0 \%$ with respect to the control. The rate of decline in PV was highest in the oil sample stabilized with pomegranate peel extracts $(70.0 \%)$, followed by apple peel $(64.6 \%)$, citrus peels $(61.6 \%)$, banana peels $(58.4 \%)$, corncob $(55.8 \%)$, BHT $(55.3 \%)$, wheat bran $(53.6 \%)$, rice bran $(51.3 \%)$, wheat husk (48.8\%), and rice hull $(42.5 \%)$ (Table 3).

Peroxide value is often used as a measurement of the oxidative deterioration of oil, fat and fatty foods, hence, efficacy of an antioxidant extract to prevent or delay the onset of oxidation could be predicted by the rate of formation of these primary oxidation products. Oil stabilized with synthetic or natural antioxidants usually shows lower PV and extended induction periods (Anwar et al., 2007; Chatha et al., 2006; Siddiq et al., 2005). The decline in PV of soybean oil stabilized with a crude methanolic extract from rice bran at the end of a incubation period (at $60^{\circ} \mathrm{C}$ ) of 15 days was $32.7 \%$ (Devi et al., 2007). Zia-ur-Rehman, (2006) reported the antioxidant activity of citrus peels extracts for the stabilizing of corn oil stored at 25 ${ }^{\circ} \mathrm{C}$ for a period of 6 months. The results of Zia-urRehman, (2006) indicated a rapid decline in the PV (89.9-93.9\%) of oil samples stabilized with citrus peel extracts at different concentrations. Chatha et al., (2006) reported the decline in PV (22.2-45.6\%) of sunflower oil using 100 and $80 \%$ acetone and methanolic extracts from rice bran. 


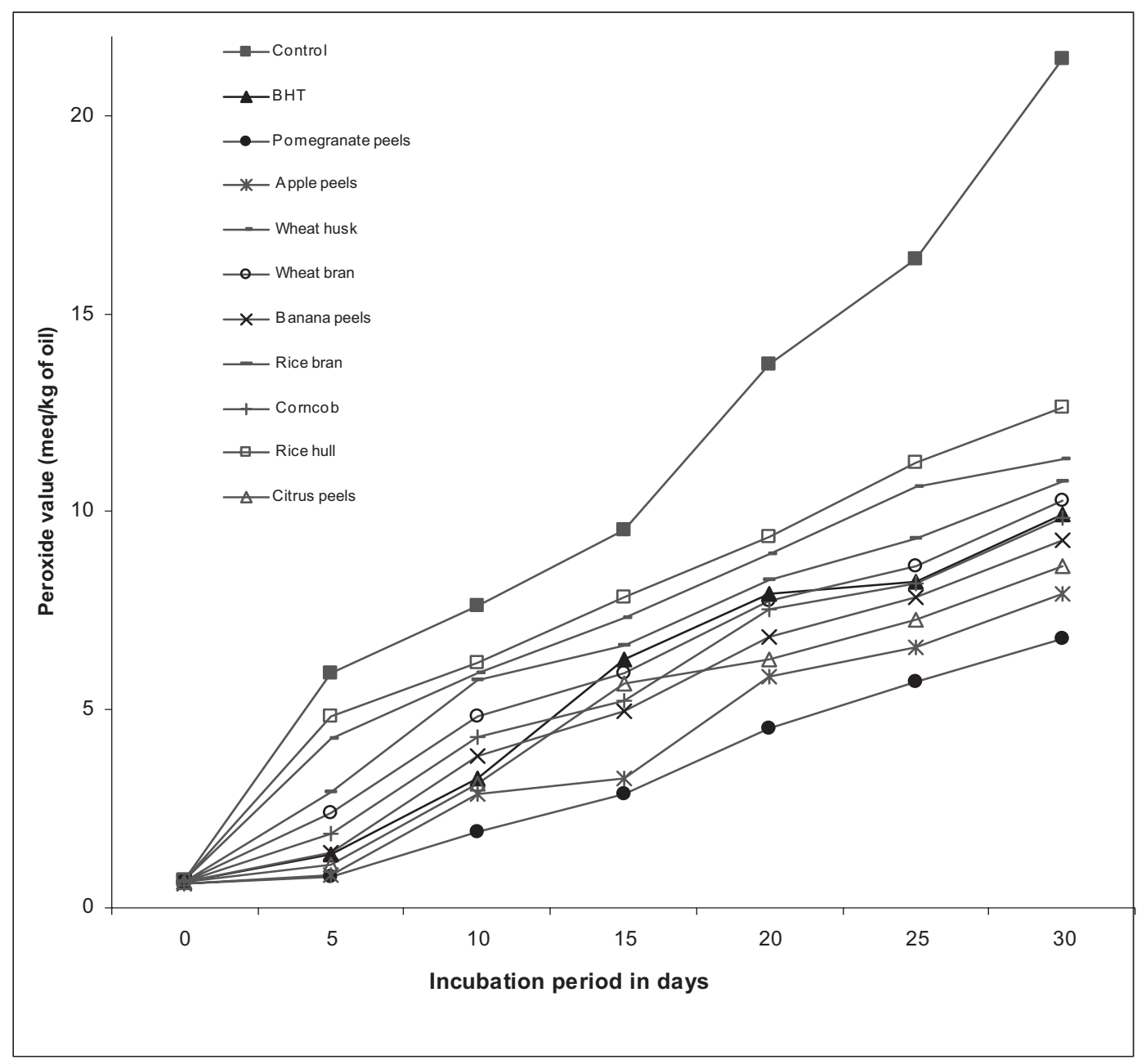

Figure 1

Peroxide value (meq/kg of oil) of stabilized and control corn oil.

The difference in the results of these studies with our investigation may be due to the nature of substrate oil, variations in storage conditions and concentration of the extract used. However, in all such cases lower values for PV for oils with antioxidant extracts as compare to the control showed the effectiveness of the extracts in preventing the oxidation of the oil.

Conjugated diene (CD) and triene (CT) contents of corn oil samples stabilized with methanolic extract of different plant materials, BHT and control are shown in Figures 2 and 3. The CD and CT

Table 3

Alteration in oxidation parameters of stabilized corn oil at the end of incubation period

\begin{tabular}{|c|c|c|c|c|c|c|c|c|}
\hline & \multicolumn{2}{|c|}{ PV } & \multicolumn{2}{|c|}{ CD } & \multicolumn{2}{|c|}{ CT } & \multicolumn{2}{|c|}{ PA } \\
\hline & $\begin{array}{l}\text { Increase } \\
\text { from initial }\end{array}$ & $\begin{array}{c}\% \\
\text { decline }\end{array}$ & $\begin{array}{l}\text { Increase } \\
\text { from initial }\end{array}$ & $\begin{array}{c}\% \\
\text { decline }\end{array}$ & $\begin{array}{l}\text { Increase } \\
\text { from initial }\end{array}$ & $\begin{array}{c}\% \\
\text { decline }\end{array}$ & $\begin{array}{l}\text { Increase } \\
\text { from initial }\end{array}$ & $\begin{array}{c}\% \\
\text { decline }\end{array}$ \\
\hline $\begin{array}{l}\text { BHT } \\
\text { Pomegranato }\end{array}$ & 9.27 & 55.3 & 6.0 & 62.3 & 5.94 & 47.8 & 8.61 & 33.3 \\
\hline $\begin{array}{l}\text { Pomegranate } \\
\text { peels }\end{array}$ & 6.22 & 70.0 & 4.49 & 71.8 & 4.66 & 59.1 & 5.74 & 51.2 \\
\hline Apple peels & 7.33 & 64.4 & 4.97 & 68.8 & 4.99 & 56.2 & 4.2 & 43.9 \\
\hline Wheat husk & 10.63 & 48.8 & 9.32 & 41.5 & 7.11 & 37.5 & 4.83 & 23.0 \\
\hline Wheat bran & 9.62 & 53.6 & 6.7 & 57.9 & 6.24 & 45.2 & 6.63 & 27.9 \\
\hline Banana peels & 8.62 & 58.4 & 5.61 & 64.8 & 5.7 & 49.9 & 6.21 & 35.8 \\
\hline Rice bran & 10.1 & 51.3 & 8.61 & 45.9 & 6.54 & 42.5 & 5.53 & 25.3 \\
\hline Corncob & 9.17 & 55.8 & 5.97 & 62.5 & 5.97 & 47.5 & 6.43 & 33.4 \\
\hline Rice hull & 11.95 & 42.5 & 9.83 & 38.3 & 7.6 & 33.2 & 5.73 & 19.2 \\
\hline Citrus peels & 7.97 & 61.6 & 5.56 & 65.1 & 5.26 & 53.8 & 5.18 & 39.8 \\
\hline
\end{tabular}




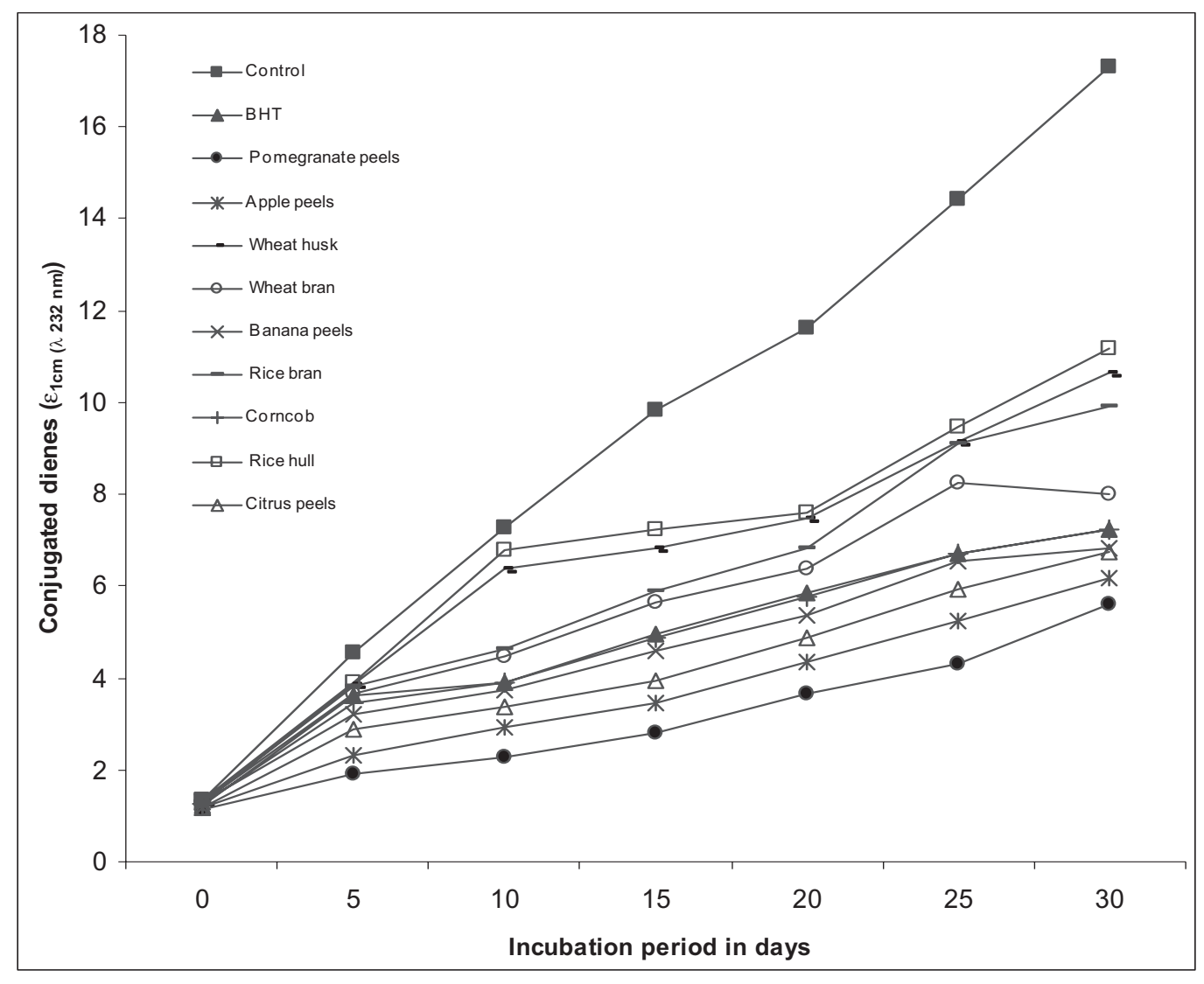

Figure 2

Conjugated dienes $\left(\varepsilon_{1 \mathrm{~cm}(\lambda 232 \mathrm{~nm})}\right)$ of stabilized and control corn oil.

contents increase paralleled the increase in incubation period with the highest rates for the control. The oil samples stabilized with plant extract showed lower levels of CD and CT as compared to the control, indicating the antioxidant potential of the extracts from the investigated plant materials. A decline in the rise of CD (38.3-71.8\%) and CT (33.2-59.1\%) in corn oil samples (Table 3 ) stabilized with plant extracts as compared with that of the control might be attributed to the presence of natural antioxidant components within these extracts. The lowest level of CD was noted for corn oil samples stabilized with the extract of pomegranate peel, followed by apple peels, citrus peels, banana peel, corncob, wheat bran, rice bran, wheat husk, and rice hull.

Devi et al., (2007) reported a decline in the rise of conjugated dienes in soybean oil up to $38.1 \%$ as compared to a control using a methanolic extract from rice bran. Chatha et al., (2006) also concluded that the addition of 100 and $80 \%$ acetone and methanolic extracts from rice bran reduced the formation CD, CT in sunflower oil stabilized under ambient conditions (room temperature) up to levels of $39.2-54.9 \%$ and $11.1-36.1 \%$, respectively. Anwar et al., (2007) also investigated the stabilization of sunflower oil under ambient aging using Moringa oleifera leaf extracts by estimating CD and CT contents, thus evaluating the antioxidant potential of Moringa leaves. The antioxidant activity of garlic extracts in sunflower oil was also assessed under accelerated conditions, using $\mathrm{CD}$ and $\mathrm{CT}$ as indicators of oxidative degradation (Iqbal and Bhanger, 2007).

Measurement of CD and CT are reliable parameters for predicting the oxidative stability of oils. Lipids containing methylene-intrupted dienes or polyenes show a shift in their double bond position during oxidation. The resulting conjugated dienes exhibit intense absorption at $232 \mathrm{~nm}$; similarly conjugated trienes absorb at $268 \mathrm{~nm}$. The increase in CD and CT contents is proportional to the oxygen intake. The greater the levels of CD and $\mathrm{CT}$, the higher the magnitude of oxidative degradation will be, thus indicating a lower oxidative stability of the oils (Anwar et al., 2007; Siddiq et al., 2005; Chatha et al., 2007).

Figure 4 depicts the level of $p$-anisidine values for corn oil samples stabilized with methanolic extracts, $\mathrm{BHT}$, and the control. The periodical analysis of the oil samples with and without antioxidant extracts as a function of storage time revealed a decline in $p$ anisidine values (33.2-59.1\%) (Table 3) as compared to the control. In the control sample, formation of carbonyls was significantly $(P<0.05)$ higher as compared to samples with added extracts. Pomegranate peel extract was found to be the most effective in retarding the formation of carbonyl components as measured by the $p$-anisidine value (59.1\% decline), while rice hull displayed the least 


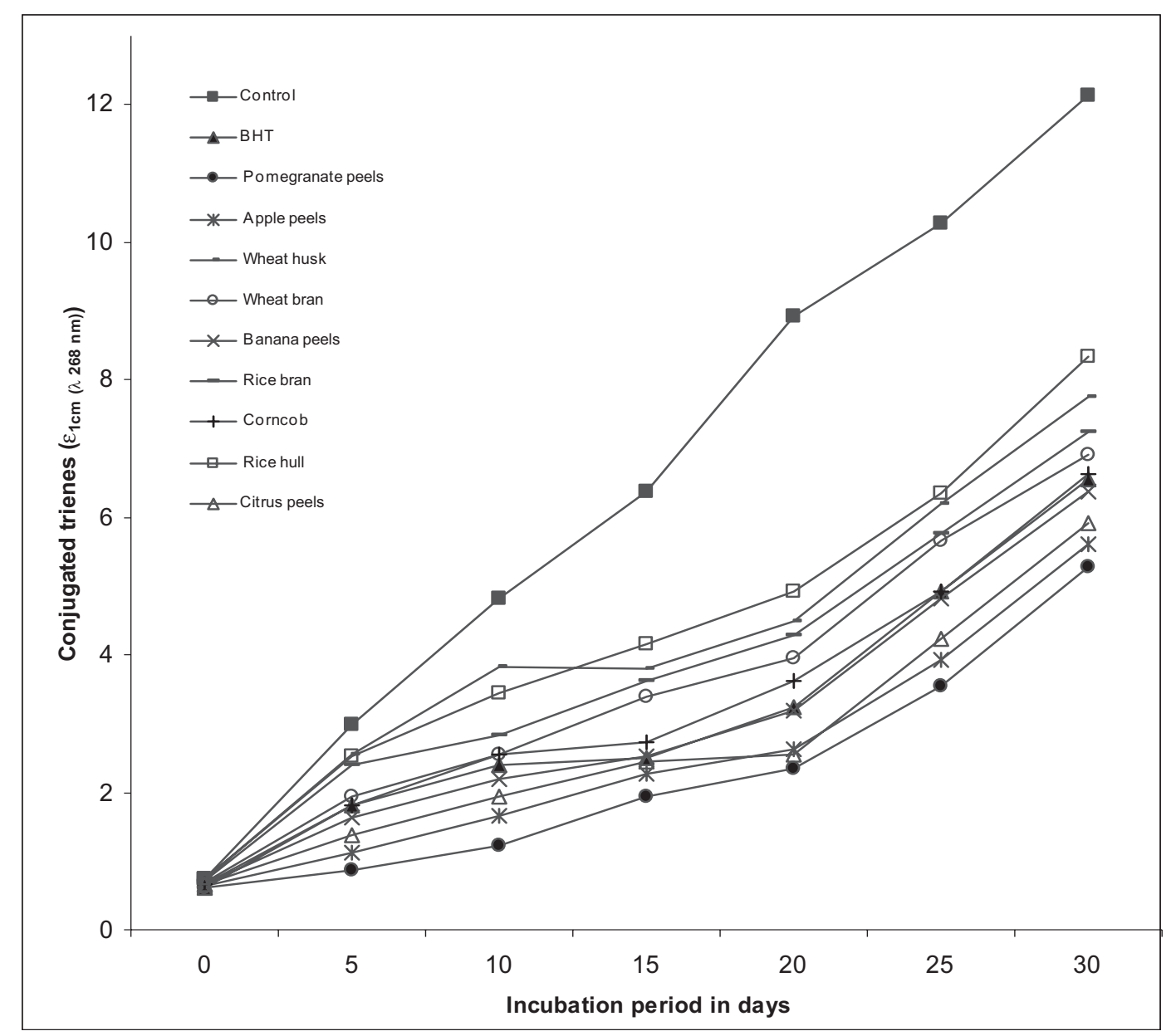

Figure 3

Conjugated trienes $\left(\varepsilon_{1 \mathrm{~cm}(\lambda 268 \mathrm{~nm})}\right)$ of stabilized and control corn oil.

efficiency (33.2\% decline) (Table 3). Devi et al., (2007) reported a decline in $p$-anisidine values in soybean oil stabilized $\left(\right.$ at $60^{\circ} \mathrm{C}$ ) with crude methanolic extracts of rice bran up to $24.0 \%$ at the end of an incubation period of 15 days. In another study (Chatha et al., 2007), the decline in $p$-anisidine value of sunflower oil stabilized (ambient storage) with 100 and 80\% acetone and methanolic extracts of rice bran ranged from $20.6-51.1 \%$. The extent of the decline in $p$ anisidine value in the present study was $33.2-59.1 \%$ (Table 3). The measurement of $p$-anisidine value to assess the potential of natural antioxidants in vegetable oils under accelerated storage conditions is generally accepted (Chatha et al., 2007). The measurement of $p$-anisidine value is extensively used to assess secondary oxidation products, mainly nonvolatile carbonyls (2-alkenal and 2, 4 alkadienal) formed during the lipid oxidative degradation of oils and fats. Aldehydes in oil and the $p$-anisidine reagent react with each other under acidic conditions, resulting in the formation of a yellowish colored product, whose concentration is determined spectrophotometrically by measuring absorbance at $350 \mathrm{~nm}$. The greater the absorbance, the greater the concentration of aldehydes will be, thus indicating the poor oxidative state of the oil (Anwar et al., 2007).

\subsection{Correlation between the results of antioxidant assays and oxidative parameters}

The relationship between the results of antioxidant assays with that of the oxidative parameters established by the Pearson productmoment correlation coefficient $(r)$ is shown in Table 4. A moderate correlation i.e. -0.677 , $-0.507,-0.592$, and -0.711 between total phenolic contents and peroxide, conjugate dienes, conjugate trienes and $p$-anisidine values, respectively, was demonstrated; however, a fairly strong relationship was established between total flavonoid contents and these oxidation parameters. A strong correlation was also observed i.e. $0.962,0.957,0.980$, and 0.933 between the results of the DPPH radical scavenging assay and peroxide, conjugate dienes, conjugate trienes and $p$-anisidine values, respectively. The correlation between \% inhibition of peroxidation and oxidation parameters was also strong (Table 4). From the results of the correlation analysis it could be declared that the antioxidant components of plant extracts are accountable for the enhancement of the oxidative stability of the vegetable oil under investigation. 


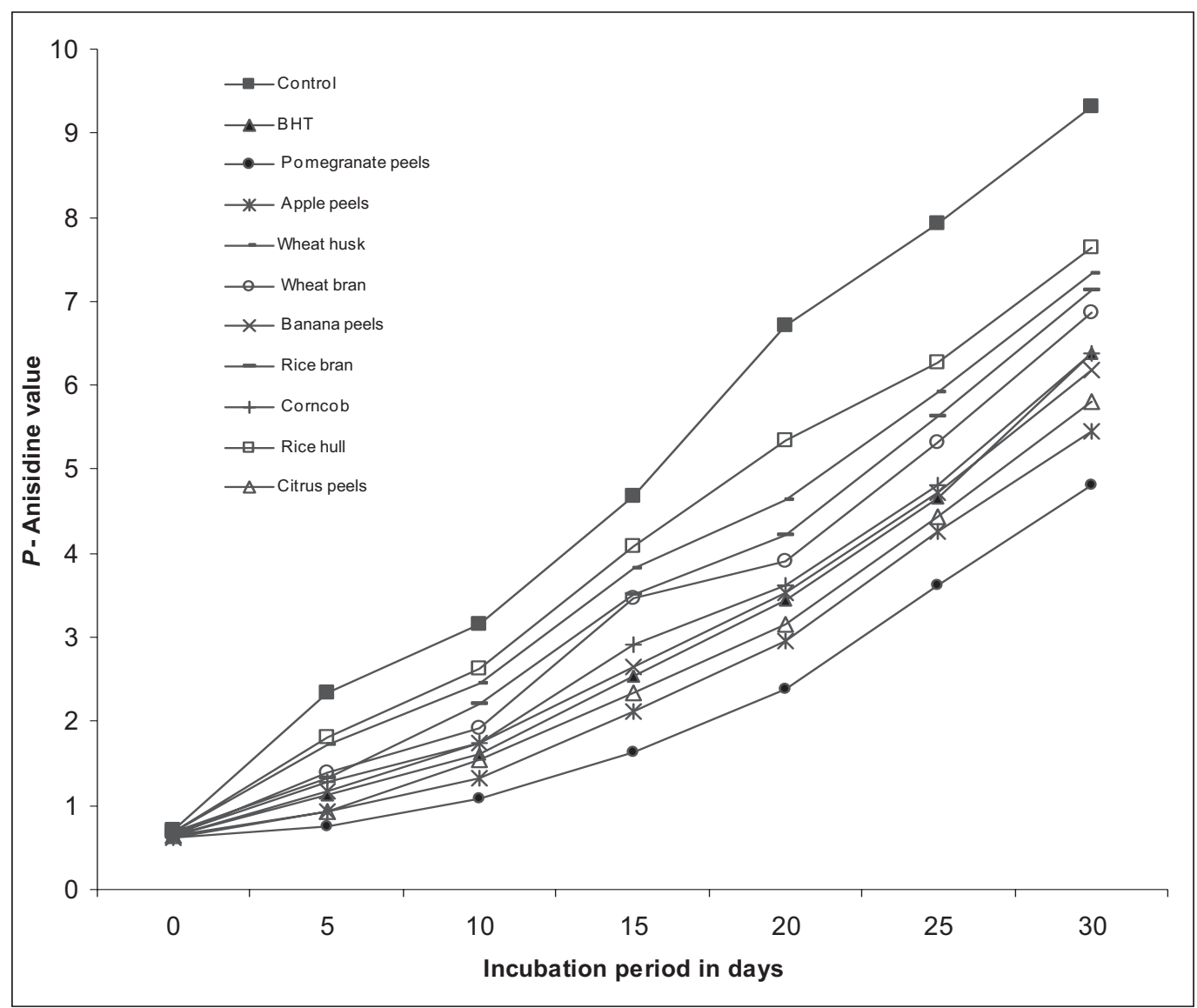

Figure 4

Para-anisidine value of stabilized and control corn oil.

\section{CONCLUSION}

From the results of present investigations it is reasonable to say that the methanolic extracts of different plant materials have exhibited varying degrees of total phenolic contents and antioxidant activities. HPLC data indicate that fruit peels contain greater contents of flavonols (myricetin, quercetin, kaempeferol). The correlation between the results of antioxidant assays and the oxidative parameters of corn oil demonstrated that fruit peel extracts which have higher antioxidant activity are

Table 4

Correlation between the results of different antioxidant assays and oxidation parameters of stabilized corn oil

\begin{tabular}{|c|c|c|c|c|c|}
\hline & TPC & TFC & $\begin{array}{c}\text { Total } \\
\text { flavonols }\end{array}$ & $\begin{array}{l}\text { DPPH remaining } \\
\text { of peroxidation }\end{array}$ & $\%$ inhibition \\
\hline $\begin{array}{l}\text { TPC } \\
\text { TFC } \\
\text { DPPH. }\end{array}$ & $0.901, P^{-}=0.000$ & $\begin{array}{c}0.901, P=0.000 \\
-\end{array}$ & $\begin{array}{l}0.909, P=0.000 \\
0.987, P=0.000\end{array}$ & $\begin{array}{l}-0.552, P=0.003 \\
-0.720, P=0.000\end{array}$ & $\begin{array}{l}0.686, P=0.000 \\
0.909, P=0.000\end{array}$ \\
\hline $\begin{array}{l}\text { Remaining } \\
\% \text { inhibition }\end{array}$ & $-0.552, P=0.003$ & $-0.720, P=0.000$ & $-0.725, P=0.002$ & - & $-0.833, P=0.000$ \\
\hline $\begin{array}{l}\text { of peroxidation } \\
\text { Peroxide value } \\
\text { Conjugated }\end{array}$ & $\begin{array}{c}0.686, P=0.000 \\
-0.677, P=0.045\end{array}$ & $\begin{array}{c}0.909, P=0.000 \\
-0.803, P=0.002\end{array}$ & $\begin{array}{c}0.920, P=0.000 \\
-0.759, P=0.021\end{array}$ & $\begin{array}{c}-0.833, P=0.000 \\
0.962, P=0.000\end{array}$ & $-0.962, \bar{P}=0.000$ \\
\hline $\begin{array}{l}\text { dienes } \\
\text { Conjugate }\end{array}$ & $-0.507, P=0.164$ & $-0.606, P=0.041$ & $-0.542, P=0.078$ & $0.957, P=0.000$ & $-0.878, P=0.002$ \\
\hline $\begin{array}{l}\text { trienes } \\
P \text { - ansidine }\end{array}$ & $-0.592, P=0.093$ & $-0.736, P=0.034$ & $-0.677, P=0.043$ & $0.980, P=0.000$ & $-0.945, P=0.000$ \\
\hline value & $-0.711, P=0.032$ & $-0.834, P=0.002$ & $-0.782, P=0.0032$ & $0.933, P=0.000$ & $-0.976, P=0.000$ \\
\hline
\end{tabular}

Correlation analysis between different antioxidant assays and oxidative parameters $(n=3 \times 3)$ were described as Pearson productmoment correlation coefficient (r). Results are statistically significant at $P<0.05$. TPC, Total Phenolic Contents: TFC, Total Flavonoid Contents. 
more potent towards enhancing the oxidative stability of corn oil. Hence, the agro materials investigated can be explored as a potential antioxidant source of natural origin; however, it is recommended that the cytotoxicity of the investigated extracts be investigated before their applications in vegetable oils, functional foods or nutraceuticals.

\section{REFERENCES}

Abrosca BD, Pacifico S, Cefarelli G, Mastellone C, Fiorentino A. 2007. "Limoncella, apple an Italian apple cultivar: phenolic and flavonoid contents and antioxidant activity. Food Chem. 104, 1333-1337.

American Oil Chemists Society (AOCS). 1997. Official Methods and Recommended Practices of the AOCS, 5th edn., AOCS Press, Champaign.

Anagnostopoulou MA, Kefalas P, Papageorgiou VP, Assimopoulou AN, Boskou D. 2006. Radical scavenging activity of various extracts and fractions of sweet orange peel (Citrus sinensis). Food Chem. 94, 19-25.

Anwar F, Siddiq A, Iqbal S, Asi MR. 2007. Stabilization of sunflower oil with Moringa oleifera leaves under ambient storage. J. Food Lipid 14, 35-49.

Chaovanalikit A, Wrolstad RE. 2004. Total anthocyanins and total phenolics of fresh and processed cherries and their antioxidant properties. J. Food Sci. 69, 6772.

Chatha SAS, Anwar F, Manzoor M, Bajwa JR. 2006. Evaluation of the antioxidant activity of rice bran extracts using different antioxidant assays. Grasas $Y$ Aceites 57, 328-335.

Cheng Z, Su L, Moore J, Zhou K, Luther M, Yin JJ, Yu LL. 2006. Effect of postharvest treatment and heat stress on availability of wheat antioxidants. J. Agric. Food Chem. 54, 5623-5629.

Choi Y, Jeong HS, Lee J. 2007. Antioxidant activity of methanolic extracts from some grains consumed in Korea. Food Chem. 103, 130-138.

Dewanto V, Wu X, Adom KK, Liu R.H. 2002. Thermal processing enhances the nutritional value of tomatoes by increasing total antioxidant activity. $\mathrm{J}$. Agric. Food Chem. 50, 3010-3014.

Devi RR, Jayalekshmy A, Arumughan C. 2007. Antioxidant efficacy of phytochemical extracts from defatted rice bran in the bulk oil system. Food Chem. 104, 658-664.

Fan J, Ding X, Gu W. 2007. Radical-scavenging proanthocyanidins from sea buckthorn seed. Food Chem. 102, 168-177.

Gil MI, Tomas-Barberan FA, Hess-Pierce B, Holeroft DM, Kadar AA. 2000. Antioxidant activity of pomegranate juice and its relationship with phenolic composition and processing. J. Agric. Food Chem. 48, 4581-4589.

Hsu B, Coupar IM, Ng K. 2006. Antioxidant activity of hot water extract from the fruit of the Doum palm, Hyphaene thebaica. Food Chem. 98, 317-328.

Huang D, Ou B, Prior RL. 2005. The chemistry behind antioxidant capacity assays. J. Agric. Food Chem. $\mathbf{5 3}$, 1841-1856.

lqbal S, Bhanger MI, Anwar F. 2005. Antioxidant properties and components of some commercially available varieties of rice bran in Pakistan. Food Chem. 93, 265-272.
Iqbal S, Bhanger MI. 2007. Stabilization of sunflower oil by garlic extract during accelerated storage. Food Chem. 100, 246-254.

lqbal S, Bhanger MI and Anwar F. 2007. Antioxidant properties and components of bran extracts from selected wheat varieties commercially available in Pakistan. LWT 40, 361-367.

International Union of Pure and Applied Chemistry (IUPAC). 1987. Standard Methods for the Analysis of Oils, Fats and Derivatives, 7th Rev. edited by C. Paquot and A. Hautfenne, Blackwell Scientific, London.

Kahkonen M.P, Hopia AI, Vuorela HJ, Rauha JP, Pihlaja K, Kujala TS, Heinonen M. 1999. Antioxidant activity of plant extracts containing phenolic compounds. J. Agric. Food Chem. 47, 3954-3962.

Karadeniz F, Burdurlu HS, Koca N, Soyer Y. 2005. Antioxidant activity of selected fruits and vegetables grown in Turkey. Turk. J. Agric. 29, 297-303.

Kim JS. 2005. Radical scavenging capacity and antioxidant activity of $E$ vitamin fraction in rice bran. $J$. Food Sci. 70, 208-213.

Leontowicz H, Gorinstein S, Lojek A, Leontowicz M, Ci ZM, Soliva-Fortuny R, Park YS, Jung ST, Trakhtenberg S, Martin-Belloso O. 2002. Comparative contents of some bioactive compounds in apples, peaches and pears and their influence on lipids and antioxidant capacity in rates. J. Nutr. Biochem. 13, 603-610.

Li Y, Guo C, Yang J, Wei J, Xu J, Cheng S. 2006. Evaluation of antioxidant properties of pomegranate peel extract in comparison with pomegranate pulp extract. Food Chem. 96, 254-260.

Liyana-Pathirana CM, Shahidi F. 2007. Antioxidant and free radical scavenging activities of whole wheat and milling fractions. Food Chem. 101, 1151-1157.

Moure A, Cruz JM, Franco D, Dominguez JM, Sineiro J, Dominguez H, Nunez MJ, Parjo JC. 2001. Natural antioxidants from residual sources. Food Chem. 72, 145-171.

Negi PS, Jayaprakasha GK, Jena BS. 2003. Antioxidant and antimutagenic activities of pomegranate peel extracts. Food Chem. 80, 393-397.

Okonogi S, Duangrat C, Anuchpreeda S, Tachakittirungrod S, Chowwanapoonpohn S. 2007. Comparison of antioxidant capacities and cytotoxicities of certain fruit peels. Food Chem. 103, 839-846.

Roginsky V, Lissi EA. 2005. Review of methods to determine chain breaking antioxidant activity in food. Food Chem. 92, 235-254.

Shahidi F. 1997. Natural Antioxidants, Chemistry, Health Effects and Applications. Champaign, IL, USA: AOCS Press, Champaign.

Siddhuraju P, Becker K. 2007. The antioxidant and free radical scavenging activities of processed cowpea (Vigna unguiculata L.) see extracts. Food Chem. 101, 10-19.

Siddiq A, Anwar F, Manzoor M, Fatima A. 2005. Antioxidant activity of different solvent extracts of Moringa oleifera leaves under accelerated storage conditions of sunflower oil. Asian J. Plant Sci. 4, 630635.

Someya S, Yoshiki Y, Okubo K. 2002. Antioxidant compounds from bananas (Musa cavendish). Food Chem. 79, 351-354.

Sultana B, Anwar F, Przybylski R. 2007. Antioxidant activity of phenolic components present in barks of Azadirachta indica,Terminalia arjuna, Acacia nilotica, 
and Eugenia jambolana Lam. trees. Food Chem. 104, 1106-1114.

Sikwese FE, Duodu KG. 2007. Antioxidant effects of crude phenolic extracts from sorghum bran in sunflower oil in the presence of ferric ions. Food Chem. 104, 324-331.

Tokusoglu O, Unal MK, Yildirum Z. 2003. HPLC-UV and GC-MS characterization of the flavonol aglycons quercetin, kaempferol and myrecetin in tomato and tomato pastes and other tomato-based products. Acta Chromatographica 13, 196-207.

Wang SY, Chang HN, Lin KT, Lo CP, Yang NS, Shyur LF. 2003. Antioxidant properties and phytochemical characteristics of extracts from Lactuca indica. J. Agric. Food Chem. 51, 1506-1512.
Wang YC, Chuang YC, Ku YH. 2007. Quantitation of bioactive compounds in citrus fruits cultivated in Taiwan. Food Chem. 102, 1163-1171.

Wolfe KL, Liu RH. 2003. Apple peels as a value-added food ingredient. J. Agric. Food Chem. 51, 1676-1683.

Yen GC, Duh PD, Chuang DY. 2000. Antioxidant activity of anthraquinones and anthrone. Food Chem. 70, 307-315.

Zhou K, Yu L. 2004. Effects of extraction solvent on the wheat bran antioxidant activity estimation. LWT 37, 717-721.

Zia-ur-Rehman. 2006. Citrus peel extract- A natural source of antioxidant. Food Chem. 99, 450-454.

Recibido: $22 / 10 / 07$ Aceptado: 16/1/08 